\title{
MIR19B2 Pre-miRNA
}

National Cancer Institute

\section{Source}

National Cancer Institute. MIR19B2 Pre-miRNA. NCI Thesaurus. Code C82710.

MIR19B2 pre-miRNA is an olig oribonucleotide that is encoded by the human MIR19B2

gene and is involved in the regulation of gene expression. 